\title{
"Fleshing Out Consensus": Radical Pragmatism, Civil Rights, and the Algebra Project
}

\author{
Jessica T. Wahman
}

\begin{abstract}
It has been said that pragmatism's "merely instrumental" truths fail to motivate radical change whereas absolute ideals make excellent guiding and driving forces for justice. However, in Radical Equations: Math Literacy and Civil Rights, Robert Moses speaks of the radical success of pragmatic principles, used in the Civil Rights Movement, that are continued today in the Algebra Project. This paper applies Dewey's claims about education and community to Moses's own arguments as a means of depicting the role that pragmatic ideals play in achieving radical social change.
\end{abstract}

There have been rumblings of late that the pragmatic method, despite its many benefits, is not capable of effecting truly radical social change. We hear that pragmatism's emphases on deliberation and problem solving render it too inefficient to combat existing and concrete structures of oppression. Furthermore, the "merely instrumental" truths that emerge from such discussion fail to impel people from talk to action: no one puts one's life on the line for a merely pragmatic ideal. ${ }^{1}$ By contrast, absolute ideals apparently make for an excellent guiding and driving force in the battle against injustice; their authority and power are drawn from a higher source and their worth, due to such origins, is incontrovertible. Ideals like these are worth dying for, the argument goes, and faith in them provides the motivation necessary to propel people out of the committee room and into the streets, where change can actually occur. After all, didn't Dr. Martin Luther King's appeal to a higher form of justice inspire oppressed blacks and sympathetic whites into the direct action campaigns of the Civil Rights Movement? Didn't the movement derive its power and sustenance from his religious leadership? 
Not according to Robert Moses. ${ }^{2}$ As fundamental to the success of the Movement as a charismatic leader wielding divinely inspired ideals were the pragmatic principles of consensus building within local communities. In Radical Equations: Math Literacy and Civil Rights, Moses-together with coauthor Charles Cobbdescribes the practices of Ella Baker and the Student Nonviolent Coordinating Committee (SNCC), explaining how and why SNCC's pragmatic strategies were capable of radical influence. He delineates how the practice of "fleshing out consensus" could better effect systematic change and could develop locally the foundations for sustaining political enfranchisement (Moses \& Cobb 2001, 85).

More importantly, these principles, far from being appropriate only to the time, are functioning effectively today. Drawing on his civil rights organizing experiences with SNCC, Moses carries forward the radical pragmatism of the movement into his creation of the Algebra Project. This educational project bases itself on the assertion that-just as the vote was in the Jim Crow South-mathematical literacy is a fundamental requirement for citizenship in the technological era of the twenty-first century. In keeping with this, Moses utilizes his experience with the Voting Rights Project in Mississippi to promote and develop numeracy in historically disenfranchised communities. He notes, furthermore, that while algebra and the vote may not appear to be drastic or dramatic enough factors to fundamentally alter the structures of oppression, they are as radical as sit-ins and marches-even more so in that they are more likely to achieve long-standing results. In a manner reminiscent of John Dewey, Moses speaks of them as tools that enable people to use rather than be used by the socioeconomic system and to become persons with the power to continually transform their own communities as new needs and problems arise $(13,72)$. The strategies and principles that Moses articulates in Radical Equations, particularly the notion of consensus, offer a different picture of the role that pragmatic principles played in the activism of the Civil Rights Movement and continue to operate in the educational practices of the Algebra Project. In doing so, the successes of these projects ${ }^{3}$ exemplify Dewey's arguments that education, as an inherently social institution, is fundamental to the development of a community capable of directing its own progress. Radical Equations offers us a deeper general understanding of the meaning of pragmatic ideals and their ability to foster radical change through social institutions capable of truly building community.

Bob Moses begins his explanation of the Algebra Project with a review of the Civil Rights Movement and a discussion of Ella Baker in order to trace the continuity between Baker's philosophy of activism and his own present efforts. Ella Baker's beliefs lay at the root of her disagreements with the Southern Christian Leadership Conference (SCLC), of which she was Executive Director, and deeply influenced the very different grassroots organizing practices of SNCC. ${ }^{4}$ At the heart of Baker's conflicts with SCLC lay her dislike of the hierarchy imposed by church structure. She believed that the power and attention accorded a charismatic leader-such as a moving and inspirational minister - not only made one's cause dependent on the changeable attentions of the media, but more importantly, it hindered oppressed 
people from discovering that they were ultimately both capable of and responsible for fighting the injustices perpetrated against them. At bottom, she claimed, "they cannot look for salvation anywhere but to themselves" (Moses \& Cobb 2001, 33). The "church" vision of activism - the minister as the source of direction and motivation for his flock-was counterproductive, as she saw it, to the goal of empowering individuals to make demands on both themselves and the political system and to emerge as leaders from within their own communities.

On the one hand, the purpose of focusing on everyday individuals was simply strategic. Demands are better heard and respected when they come from those who are oppressed rather than from charitable or supportive types acting on their behalf. When people speak for themselves their claims are accorded a legitimacy otherwise invalidated as the manipulative influences of "outside agitators." Moses both echoes and clarifies this point when he asserts that "[n] o matter how great Martin Luther King, Jr., was he could not go and challenge the seating of the Mississippi Democrats at Atlantic City" (20). A well-meaning outsider, no matter how inspired or uplifting, could not speak for the African American people of Mississippi and claim they wanted a voice; to make the nation believe that Mississippi blacks demanded enfranchisement, blacks from Mississippi had to stake the claim themselves. ${ }^{5}$

But this is not the whole story. Even more important than whether others choose to recognize the validity of the claims of the oppressed is the effect felt by the members of a community in finding and exercising their own voice; and understanding this effect requires entertaining a different concept of the source from which an inspirational idea derives its power. A fundamental principle of SNCC was that people do not organize to change their world by being drawn like a beacon to the visionary purposes of others; they build consensus by drawing on the concepts, values, and beliefs already embedded in their community and then utilize this consensus to alter a system that stands opposed to their needs. This principle, in which the force of an ideal does not depend on its transcendent hypostatic existence but emerges from within a particular cultural imagination as a model for change, calls to mind Dewey's pragmatic tenets about community, the nature of inquiry, and his concept of meanings as social habitual functions geared toward action.

In The Public and Its Problems, Dewey defines community in a way that sheds light on the importance of SNCC's form of grass-roots organizing: "Wherever there is conjoint activity whose consequences are appreciated as good by all singular persons who take part in it, and where the realization of the good is such as to effect an energetic desire to sustain it in being just because it is a good shared by all, there is in so far a community" $(2000,505)$. In order for values to become goals, that is, to motivate people to act on their behalf, they must resonate withthey must mean something to-each individual, both personally and as a member of a group. Moses similarly articulates the need for a foundation of shared understanding when he states that "people will not organize that kind of seminal effort [displayed at the Democratic Convention] around somebody else's agenda. It's got 
to be internalized ..." (Moses \& Cobb 2001, 20). "Internalization" does not imply that the motivation must be supplied and implanted by the organizer but that roots of the agenda must be found already entrenched within communal understanding and, as he puts it, "fleshed out" (85).

The need to develop an agenda in such a manner suggests that shared values and goals are implicit in the workings of a culture but must be translated by the members of that culture into a solution specific to the concrete problem at hand. In A Common Faith, Dewey states that an ideal "emerges when the imagination idealizes existence by laying hold of the possibilities offered to thought and action. ... We need no external criterion and guarantee for their goodness" $(1934,48)$. Rather than independent realities waiting to be noticed, ideals are instead operations born of a problematic situation and geared toward its amelioration, and they possess the power to alter social institutions. Consensus building amounts to this process of uncovering core shared meanings in the interest of radical change, as Moses affirms when he claims: "Staking out some area of consensus was necessary, but an organizer could not create consensus, an organizer had to find it. And it took time and patience to search out where it was lodged beneath layer after layer of other concerns" (85). Consensus, as described here, implies far more than assent to a proposed agenda. It is the articulation of a common need, wrought out of and upheld by the community through a practice more complex and a good deal more personal than formal processes of deliberation.

In order to begin to find a common ground on which to base action like the Voting Rights Project, the key was to learn about and from the individual members of the community. Organizers had to really get to know people-their needs, fears, and, most importantly, their interpretation of their situation-in order to help discover the possibilities for changing that situation: "The organizer becomes part of the community, learning from it, becoming aware of its strengths, resources, concerns, and ways of doing business. The organizer does not have the complete answer in advance ..." (Moses \& Cobb 2001, 112). Uncovering and developing a consensual concept like "one person, one vote" could only be accomplished with a serious respect for the world that particular individuals inhabit and the recognition that solutions do not come ready made. Reminiscent of Dewey's description of the pattern of inquiry, the organizer facilitates the construction of a solution out of a relatively indeterminate situation (Dewey 1987, 490). To be truly a process of inquiry, the answer cannot be known in advance but instead discovered through shared investigation, and therefore the organizer, if he or she is honestly engaged, must become a part of that experience by developing an internal perspective. A concept that can suggest meaningful possibilities for change must come from those who actually live and experience the problematic conditions, and their interpretation of those conditions must be the foundation for their solution.

Moses's experiences of facilitating conceptual consensus regarding the right to vote suggest that consensus-building involves more than argument; it involves adapting deep-seated habits of both action and imagination. As he relates: 
"Have you ever tried to fill out this form?" I would ask. "Would you like to sit down now and try to fill it out?" Often the response was negative. . . . But I like to think I got anyone I spoke with imagining himself or herself at the registrar's office. Getting someone to make this kind of a mental leap, even for a moment, had to be considered an achievement in the Black Mississippi of those days where even the idea of citizenship barely existed. (46)

These sorts of practices in which SNCC staff members engaged are reminiscent of Dewey's psychological thesis that ideas are not things thought in the mind so much as symbols of living operations (Dewey 1988, 26). Viewing human beings as systems of social habits, Dewey recognized the mutually reinforcing characteristic of ideas and actions. A functioning — that is, meaningful - idea amounts to an abstract representation of a habit working through the human organism, and so for an idea to be truly convincing it should fit within the realm of a person's actual experience. Changing someone's mind, then, involves adapting existing habits of thought and action so that they accommodate an unfamiliar or denied idea (26). In the case of blacks in Mississippi, the right to vote had been so long denied by the habitual influence of terror on the part of white society that responses that voting was "white folks' business" were not uncommon. SNCC volunteers had to use concrete practices and action-specific imagery in order to make citizenship seem like a reasonable and attainable ideal to those who had been forcefully habituated to deny it of themselves.

In the present day the challenge is to get African American youth to want and demand the right to understand advanced math. Moses points out that, while the ability to read is seen as a reasonable goal for all, mathematical capabilities are still viewed as the province of a talented elite, very few of whom are black: "in the culture itself - our culture-illiteracy in math is acceptable the way illiteracy in reading and writing is unacceptable. Failure is tolerated in math but not in English" (Moses \& Cobb 2001, 9). To change this, the Algebra Project builds on the existing conceptual consensus of a universal right to education that is "woven into the cultural fabric of this country" (92) and makes it specific to mathematics. As with "one person one vote," the sociocultural promise of a right contrasted with the denial of it in fact becomes the source of the consensual concept that grounds the enterprise. Through localized grassroots efforts, members of the community-teachers, parents, and other students - make the need and desire to learn advanced mathematics "culturally convincing" by actually helping students to achieve an advanced understanding of mathematics, and this thereby engages the interests of their peers (101). As with voting rights, the point is to encourage students to begin to demand-of themselves and of the system-what society claims they don't want (18).

The philosophy that core meanings act as the ground for change operates in the Algebra Project both as an organizing tool and as the basis for mathematical education itself. Drawing on Quine's theory that math is a specialized and unspoken language, Moses structures the projects so that students learn the deep meanings 
of mathematics as opposed to developing some arbitrary "skill set" (Moses \& Cobb 2001, 101). Building on Dewey's philosophy of experiential education, the students learn the flexible habits of mathematical meaning rather than the repetitive habits of rote memorization (Dewey 2000, 495). ${ }^{6}$ The key difference between these sorts of habits is that flexible ones are bases for individuals to gain new understanding on their own, and similarly, a goal of the Algebra Project is ultimately to get students to be able to solve new problems themselves (99). Through experiential projectsfor example, riding back and forth on the " $\mathrm{T}$ " in Boston and marking the stops to get a sense of the relationship between positive and negative integers - they learn the language of the technological community and hence can become voices and effectors of change within that community. ${ }^{7}$

The pragmatic practices of the Voting Rights and Algebra Projects have undoubtedly made a difference, but the question remains whether such change is radical. After all, getting people to demand the right to vote or to be educated does not necessitate overturning the existing system or embracing a revolutionary doctrine. However, Moses rejects the argument that math literacy and the vote are not radical because they merely incorporate the disenfranchised into the existing system, and he cites Ella Baker's definition of radical in response: "I use the term radical in its original meaning - getting down to and understanding the root cause. It means facing a system that does not lend itself to your needs and devising means by which you change that system" (3). These projects are radical because they attend to and actively engage specific individuals who have learned passivity and disaffection in an oppressive and neglectful system. ${ }^{8}$ Instead of destroying a flawed but functioning system to impose a utopian ideology, these practices build the basic habits that empower people to employ the existing tools of citizenship and to demand access to what society purports to offer. They provide people with the opportunity and the challenge to use the system effectively and, in return, to contribute to that system by formulating new ideas for adapting and improving its various institutions.

I began this paper by addressing the argument that pragmatism is too cautious and inefficient to effect great social change, unlike the faith-based strategies of the Civil Rights Movement, and as such, my earlier comments drew on that argued distinction. But there is evidence that Martin Luther King's own religiously grounded campaigns more closely matched the pragmatic than some have argued. Despite the fact that King appealed to a higher justice that prevailed over the unjust laws of Jim Crow, this does not mean we should confuse his practices of direct action as being in service of the religious truths themselves. As Dewey often put it, this would be confusing the ends with the means. First of all, King himself refers to direct action as a last resort rather than the primary means of effecting change. In "Letter from Birmingham Jail," King delineates the four basic steps of nonviolence and asserts that negotiation "is the very purpose of direct action" (King 1964, 79-81). Nonviolent resistance is only engaged in when negotiation breaks down or the opportunity for it is forcibly denied. The goal of activism as expressed by King is not to force others to embrace one's own vision of the truth, albeit nonviolently, 
but to insist on the right to a civic voice. Even more importantly, the Civil Rights Movement was not a religious crusade: people did not martyr themselves for an idea of justice, they put their lives on the line as a means of changing their concrete social reality for the better. In true pragmatic form, King used religious truths as a means of focusing and directing action. However much he may have relied on absolute religious truths in his arguments for change, the practices of nonviolent resistance were pragmatic engagements in discourse and problem solving, with direct action as a last resort.

With this in mind, it becomes evident that a simple distinction between pragmatic and religious truth would be misguided. A religious ideal may be pragmatic or it may be absolutist, but the opposition of religious to pragmatic truth is, in actuality, a false dichotomy. It is not the religiosity, strictly speaking, of an ideal that is in question but the origin of the force of that ideal. An absolute principle of justice may be "worth dying for," but the pragmatist would claim that it is not ideas we die for but the betterment of people's lives that they represent. Pragmatically conceived religious truths may more properly be viewed as "deeply shared meanings" rather than first and final truths from on high and on whose behalf one wages a campaign. As Dewey claims:

What I have been objecting to ... is not the idea that ideals are linked with existence and that they themselves exist, through human embodiment, as forces, but the idea that their authority and value depend upon some prior complete embodiment - as if the efforts of human beings in behalf of justice, or knowledge or beauty, depended for their effectiveness and validity upon assurance that there already exists in some supernal region a place where criminals are humanely treated, where there is no serfdom or slavery, where all facts and truths are already discovered and possessed, and all beauty is eternally displayed in actualized form. (Dewey 1934, 49)

Religious ideals can be guiding and driving forces for fundamental change without being absolutist. They do not derive their authority from the supernatural but from human beings who imagine a better life for themselves. Indeed, when religious principles are viewed in this way-that is, where the worth of human life is not subjugated to the worth of a dogmatically held concept-it offers a challenge to the sort of faithful devotion that would express itself in more extreme and violent forms.

Despite claims that pragmatism could never be bedfellows with activism, the pragmatic approach was actually in full force during the Civil Rights Movement in the consensus-building practices of SNCC, and it also played a part in the religiously inspired campaigns of SCLC and others. Furthermore, these principles on which Bob Moses and fellow SNCC staffers based their grassroots organizing are operating today in the local groups carrying on the Algebra Project. Fleshing out the consensus that students have a right to the mathematical language that will make them viable citizens is not an act of deliberation or compromise. It is a direct challenge to the existing system that relegates the technologically uninitiated poor 
to a condition of serfdom, and as such it is a both radical and ameliorative activity. Radical pragmatism gets at the root cause, and it devises means of changing an oppressive system for the better.

\section{Notes}

1. "[A deficiency of pragmatism as a school of thought is] that wants and beliefs can lead people to act in ways that are distinctly unpragmatic. Sometimes the results are destructive, but sometimes they are not. There is a sense in which history is lit by the deeds of men and women for whom ideas were things other than instruments of adjustment" (Menand 2001, 375). In The Metaphysical Club, Menand construes pragmatism as so grounded in compromise that it stymies significant action. The short response is sheer surprise: If there is a single fundamental contribution that pragmatism has made to theories of knowledge and truth, it is that knowledge is inextricable from action. Truth both emerges from and informs the activities and choices that people make, and this includes activities in the service of radical change.

2. Radical Equations was coauthored by Moses and fellow SNCC member Charles Cobb, but as the text reads, by and large, from the first person perspective of Moses, I have chosen to treat the arguments generally as Moses's own.

3. The greater enfranchisement of African Americans-both as voters and elected officials-is one documented measure of the success of the Voting Rights project. As Martin Luther King noted in his autobiography:

The church burnings, harassment, and murders in [Mississippi] were direct results of the fact that Negro citizens could not vote and participate in electing responsible public officials who would protect the rights of all people. Many thousands had tried to register-in spite of violence, economic reprisals, and other forms of intimidation-yet in 1963 only 1,636 Negro persons were registered in the entire state. $(1998,250)$

By the year 2000, the state with the largest number of black elected officials was Mississippi, and Mississippi and Alabama together had more black elected officials $(1,628)$ than the entire nation had in 1970 (Bositis 2002, 5). Of course, there are complex causes involved, and inequities in the political and economic communities remain, but statistics demonstrate that political enfranchisement of African Americans has vastly increased, and it is reasonable to conclude that the Voting Rights Project played an early part in dismantling a system stubbornly opposed to black voters.

4. Moses refers to Baker as SNCC's "fundi," a Swahili term combining the concepts of skilled craftsperson and instructor (Moses \& Cobb 2001, 4).

5. One might be inclined to object at this point that Martin Luther King was in fact a member of the community of African Americans, had emerged from within the southern black community, and was therefore not a supportive outsider. But this, I would argue, only appears so from the point of view of contemporary identity politics. African Americans from outside particular southern counties, not to mention from states further to the north, were considered "outside agitators" as much as were the northern white students later during the Freedom Summer Project of 1964 (18).

6. Moses studied with Quine at Harvard, and teachers in the early stages of the Algebra Project were trained at Wheelock College, where they were influenced by educational theories of both Dewey and Piaget $(97,198)$. 
7. Indeed, Algebra Project participants have made their voices heard beyond the technological community by engaging in political activism. The Baltimore Algebra Project has staged repeated "die-in" demonstrations since 2004 and has engaged in more than one hunger strike (the most recent in June of 2008; www.algebra.org/news) in protest of the fact that city schools have been denied state funds that are owed them and have generally underfunded Baltimore inner city education (Loh 2004, 1; Kumar 2008, 3B; Jones 2008, 4B). Indeed, the Baltimore Algebra Project has created its own advocacy branch to keep pressure on city and state officials (http://baltimore-algebra-project.org/Home_Page.html).

8. Martin Luther King himself noted the radical power of the Voting Rights Project when he stated that

$[u]$ nder the leadership of Bob Moses, a team of more than a thousand Northern white students and local Negro citizens had instituted a program of voter registration and political action that was one of the most creative attempts I had seen to radically change the oppressive life of the Negro in that entire state and possibly the entire nation. The Negroes in Mississippi had begun to learn that change would come in that lawless, brutal police state only as Negroes reformed the political structure of the area. (King, 1998, 249, emphasis added)

\section{Works Cited}

Bositis, D. A. 2002. Black elected officials: A statistical summary 2000. Washington, DC: Joint Center for Political and Economic Studies. http://www.jointcenter. org/index.php/content/download/1809/12453/file/BEO-00.pdf

Dewey, J. 1934. A common faith. New Haven: Yale University Press. . 1988. Human nature and conduct. In The middle works of John Dewey, ed. Jo Ann Boydston. Vol. 14. Carbondale: Southern Illinois University Press.

.2000a. Education as growth. In Pragmatism and classical American philosophy, ed. J. Stuhr. ( $2^{\text {nd }}$ ed.). New York: Oxford University Press.

2000b. The pattern of inquiry. In Pragmatism and classical American philosophy, ed. J. Stuhr. ( $2^{\text {nd }}$ ed.). New York: Oxford University Press.

.2000c. Search for the great community. In Pragmatism and classical American philosophy, ed. J. Stuhr. ( $2^{\text {nd }}$ ed.). New York: Oxford University Press.

Jones, B. 2008. Students end their protest at city hall. Baltimore Sun, May 16, B4.

King, M. L., Jr. 1998. The autobiography of Martin Luther King, Jr. Ed. C. Carson. New York: Warner Books.

1964. Letter from Birmingham jail. In Why we can't wait, pp. 64-84. New York: Harper and Row.

Kumar, R. 2008. 25 Education protesters detained; at State House, students, teacher call "historic underfunding" of schools a "crime." Baltimore Sun, February 7, B3.

Loh, L. 2004. City students lie down in protest over state's lack of school funding. Baltimore Sun, December 8, 3B. http://www.baltimoresun.com/news/education/ bal-md.hunger08dec08,0,3391946.story?coll=bal-education-top 
Menand, L. 2001. The metaphysical club. New York: Farrar, Straus and Giroux.

Moses, R. P. and C. E. Cobb, Jr. 2001. Radical equations: Math literacy and civil rights. Boston: Beacon Press.

Jessica T. Wahman is Associate Professor of Philosophy at Dickinson College. E-mail: wahmanj@dickinson.edu 